\title{
Development of a Temperature Fixed Point Cell using High-Purity Aluminium
}

\author{
Januarius V. Widiatmo*, Katsuhiko HARAdA* and Masaru ARAI*
}

\begin{abstract}
Aluminium point cells have been constructed on the basis of a new metal-filling method. High-purity aluminium (6N nominal), purchased as a single rod and as pellets, were used in the newly constructed cells. The new method for filling aluminium was customized for each cell according to the form of aluminium used. Measurements have been conducted on the newly constructed cells as well as on an existing one to evaluate any improvement that may be brought by the proposed cell design and metal-filling method. The measurements include temperature measurements during the solidification of aluminium within each cell from which its freezing curve is obtained, and direct comparative measurements among cells from which the difference in the aluminium point realized among the cells is determined. Both measurements indicate that the proposed method significantly reduces the uncertainty of fixed-point realization.
\end{abstract}

Key Words : temperature standard, ITS-90, aluminium freezing point, fixed-point cell, low impurity

\section{Introduction}

The freezing points of some metals, including indium, tin, zinc, aluminium and silver, are assigned by the International Temperature Scale of $1990{ }^{\circ}$ (ITS-90) ${ }^{1)}$ as its fixed points. The freezing points are generally realized by controlling the process of melting and freezing of a highpurity fixed-point metal within a fixed-point cell. The ITS-90 states, in its supplementary information, that all metals should be nominally 99.9999\% (6 nines, $6 \mathrm{~N}$ ) pure for calibration of a standard platinum resistance thermometer (SPRT) to the highest possible accuracy. It also estimates that an uncertainty of a few millikelvins may arise in the realization of the aluminium and silver point fixed points due to the existence of impurities in fixedpoint metal of $6 \mathrm{~N}$ nominal purity. The uncertainty comes from a departure of the realized freezing point from that defined by the ITS-90 for ideally pure metal. Such uncertainty, particularly for high-temperature fixed points, appears as the most dominant uncertainty source ${ }^{2), 3}$. In order to obtain a highly accurate temperature scale, therefore, the reduction of the impurity effect is essential.

Most of the fixed-point metals assigned in the ITS-90 available at the present time have the purest level of $6 \mathrm{~N}$, and some $6 \mathrm{~N} 5$ or $7 \mathrm{~N}$. Such a high grade of fixed-point

* National Metrology Institute of Japan (NMIJ), National Institute of Advanced Industrial and Technology (AIST)

(Received April 27, 2005)

(Revised September 27, 2005) metals may deteriorate after the fabrication of its fixedpoint cell if any inadequate handling or filling method of the fixed-point metal causes contamination from the environment. The handling of the fixed-point metal includes that during storage before being used, during the filling of metal into the fixed-point cell and after the filling. In the present work, we are interested in constructing a highly reliable fixed-point cell using a metal filling system in which contamination of the metal is effectively prevented. We will compare the newly constructed cell with the one conventionally fabricated using the same nominal purity ingot to see whether or not any improvement is achieved. In relation to the current interest in resistance thermometry to reduce the fixed-point departure, as described above, such less contaminated fixed-point cell will play a very important role, particularly in evaluating the impurity effect in fixed-point realization.

The present cell construction is first focused on aluminium under the consideration that, among the fixed-point metals in the temperature range applicable to a long-stem SPRT, aluminium is known to be the most sensitive to oxidation, and that its uncertainty due to impurities is on a few millikelvin level, so it is expected that a fixed-point cell developed on the basis of aluminium will also be adaptable to other fixed-point metals.

\section{Conventional Method for Fixed-Point Metal Filling}

High-purity metal is generally purchased as, for exam- 
ple, shots, pellets or rods, wrapped in resin or glass packaging. In the conventional method of fixed-point metal filling, a graphite crucible is filled with the metal through some melt-freeze cycles until the necessary amount is collected, due to the limited space available within the crucible. Such a conventional metal filling method is schematically illustrated in Fig. 1.

As shown in Fig. 1(a), first, some pellets are poured into a graphite crucible in which a graphite thermometerwell is also installed. A graphite cap is used to seal the crucible and to fix the thermometer well at the center of the crucible. The existence of the graphite thermometer

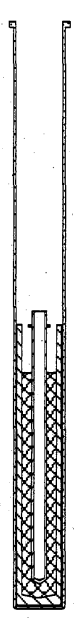

(a)

(d)

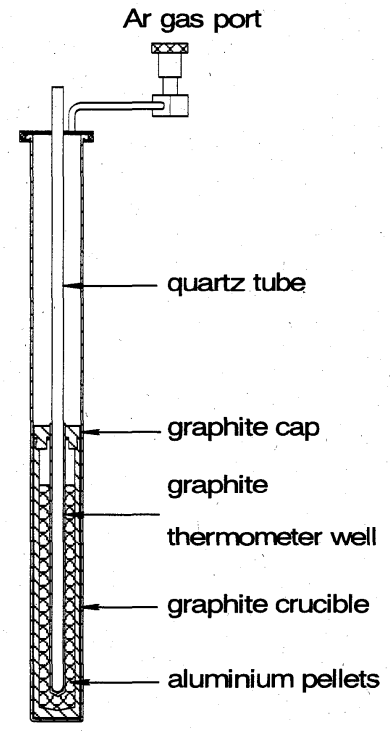

(b)

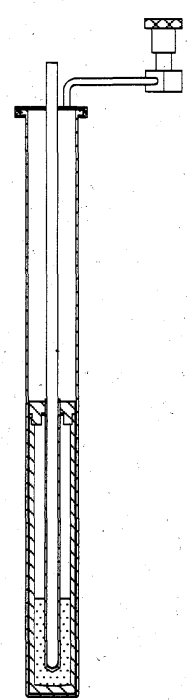

(c)
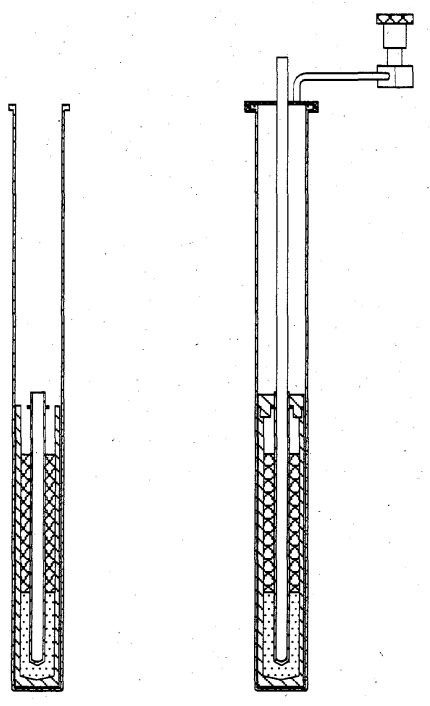

(e)

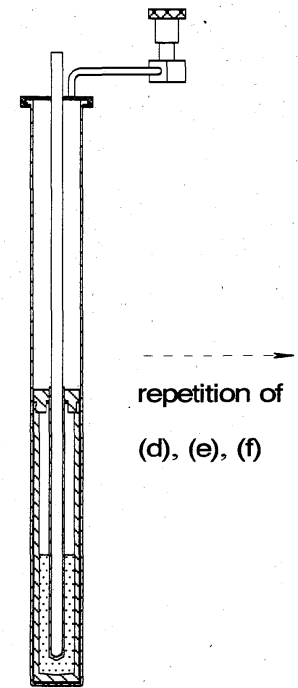

(f)
Fig. 1 Conventional metal filling method: (a) setting up the aluminium pellets, ( $b$ ) set-up before and ( c ) after the melt-freeze of the pellets, (d) to ( $f$ ) repetition of (a) to (c) using additional pellets well reduces the possible space that can be occupied by the pellets. A quartz tube closed at one end is used here to keep the graphite thermometer well vertical. The crucible and the quartz tube are enclosed in a quartz cylinder with a cap equipped with a gas port, as illustrated in Fig. 1(b).

The cylinder assembly in Fig. 1 ( $b$ ) is heated within a furnace to let the aluminium pellets melt within the graphite crucible after being degassed using a vacuum pump, then pressurized with argon gas supplied through the gas port. The temperature of the furnace is set to be some kelvins higher than the melting point of aluminium to keep it melted. The completely melted ingot fills the lowest space of the crucible, as shown in Fig. 1(c). The furnace temperature is then set some kelvins below the freezing temperature of aluminium to solidify the ingot. At the end of solidification, the temperature of the furnace is gradually reduced to room temperature.

The above procedure is also applied to additional pellets, the bulk volume of which is equivalent to the remaining space in the graphite crucible (Figs. $1(\mathrm{~d})$ to $1(\mathrm{f})$ ) and repeated until the amount necessary for fabricating one cell is obtained.

In this filling method, there are at least two considerable sources of contamination. The first one is the form of the fixed-point metal itself, i.e., the use of a number of small pellets causes the fixed-point metal to come into contact with the environment because of the extensive surface area. The existence of even a very small amount of residual oxygen and/or other contaminable gases and metal dust will produce significant contamination through such surfaces. In relation to this concern, the contamination may also have already occurred due to the imperfect isolation by the package used during storage of the fixedpoint metal. The second considerable source of contamination is the repeated melt-freeze process for casting the fixed-point metal in the graphite crucible. When additional pellets are being supplied into the graphite crucible that is already filled with metal ingot of the prior filling, both will come into contact with the environment, whereby additional contamination may occur.

Based on the above considerations, the aim of the present study is to propose a new fixed-point metal-filling method by which the possible contamination from the environment to the fixed-point metal can be reduced. To study the effectiveness of the proposed method, the present study focused on the construction of an aluminium point cell. The basic concept of the new filling method is to setup the fixed-point metal in its graphite crucible through only a single melt-freeze process or a reduced number of 
melt-freeze processes. The former is achieved here by using a single-rod fixed-point metal, with which the total surface area exposed to possible contamination can also be reduced. For this purpose, an aluminium rod $(\phi 32 \mathrm{~mm}$, $200 \mathrm{~mm}$ length, $6 \mathrm{~N}$ nominal purity) has been prepared in the present study. The latter, which is expected to be applied to the commercially available fixed-point metal, would be possible if the necessary amount of fixed-point metal can be melted at once in the graphite crucible prior to the insertion of a graphite thermometer well. However, since the crucible has a limited capacity, it is difficult to melt the entire amount of fixed-point metal into it at once. For this purpose, we propose a cell design which enables the metal melting process to be carried out only two to three times. This is still better than the four or more repeated melting processes that are required in the current filling method, so the amount of possible contamination can be reduced.

\section{New Method for Fixed-Point Metal Filling}

\section{1 Cell Design}

Similar to the conventional cell, as shown in Fig. 2, the fixed-point cell developed in the present study consists of a graphite crucible and its graphite cap, a graphite thermometer well and its holder, graphite wool as insulator, a quartz thermometer well, a quartz cylinder that contains all other parts inside, and its cap. The graphite crucible and its cap provide a space with a volume of around 223 $\mathrm{cm}^{3}$. The graphite thermometer well is cylindrical with a diameter larger at the top, smaller at the bottom, and a tapered part between them. It also has a cylindrical hole, where a quartz thermometer well is placed, at its center. The tapered part of the graphite thermometer well is the key point in this fixed-point metal-filling method as will be described later. The quartz cylinder, closed at one end, has an inner diameter of $45 \mathrm{~mm}$ and an inner volume of about $880 \mathrm{~cm}^{3}$. A stainless- ${ }^{-}$teel cap equipped with a gas port seals the other end of the cylinder. The cap also has a port for sealing the quartz thermometer well, the closed end of which is inserted into the graphite thermometer well, by means of an O-ring. This port can easily be opened or closed by removing or installing the $\mathrm{O}-$-ring and its related sealing parts. The gas port connected to a gas tank or a vacuum pump enables the pressurization of the cylinder.

A gas chamber was also prepared for all cell installations at room temperature. During the operation of the chamber, nitrogen gas or argon gas flowing through the chamber out to the atmosphere was used to flush out and

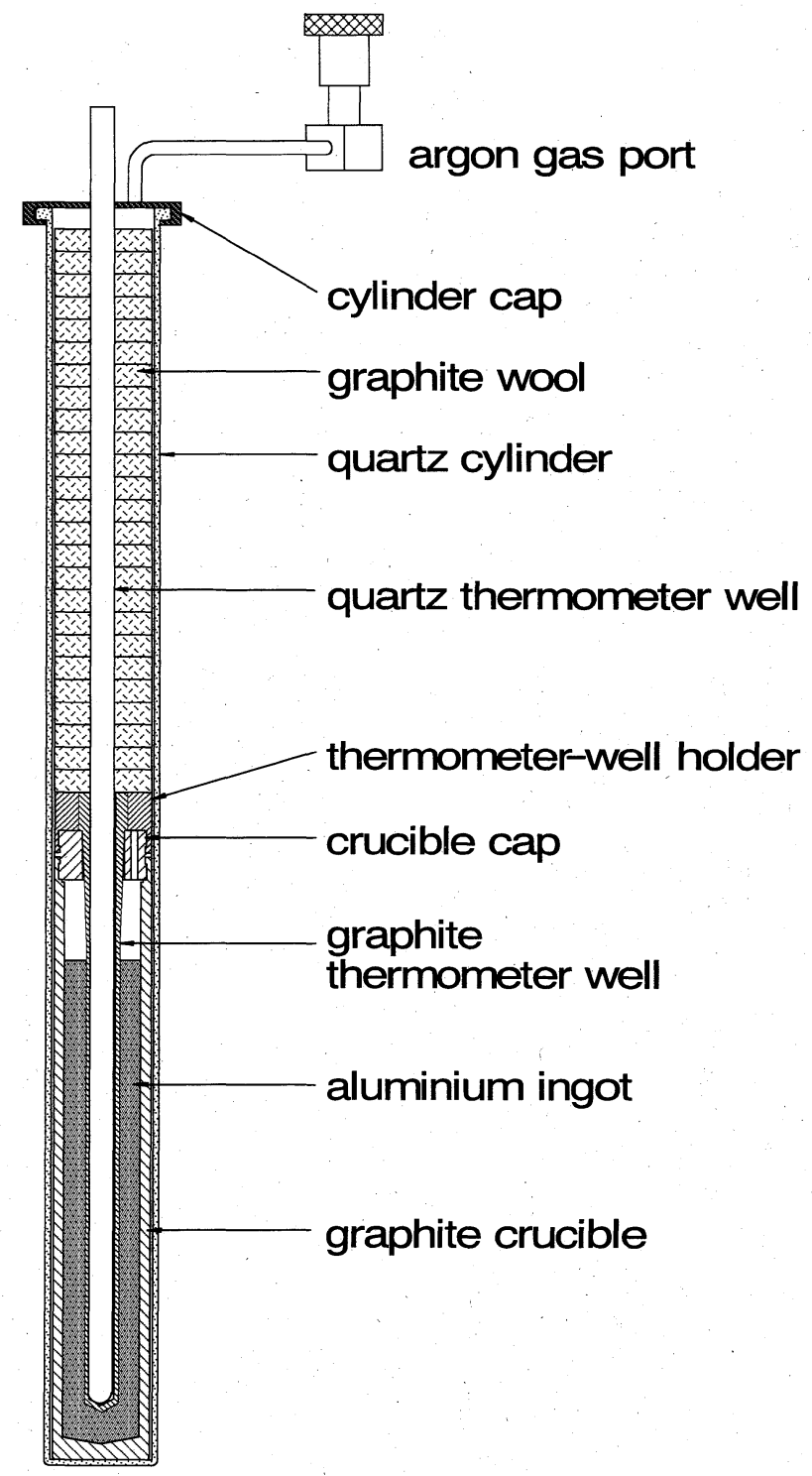

Fig. 2 Set-up of the newly developed aluminium point cell

deoxygenize the chamber. An oxygen detector was installed in the chamber to monitor the concentration of residual oxygen. The installation work was started when the concentration of the residual oxygen was lower than $0.1 \%$, particularly when the aluminium sample was installed.

\section{2 Metal-Filling Methods : Method 1}

Two filling methods depending on the form of aluminium used were investigated in the present study. One set of aluminium pellets and one single aluminium rod were prepared. The pellets were commercially available (Honeywell, Johnson-Matthey), while the rod was fabricated as part of a research project ${ }^{4}$.

In the first method proposed, Method 1, a procedure similar to that of the conventional method was applied to melt the amount of ingot necessary for fabricating one open cell, except that during this the graphite thermometer 
well was not used. This provided more space within the crucible that can be occupied by the pellets, so that number of repetitions of the metal costing procedure was significantly reduced. A quartz rod was used to seal the cylinder assembly during the metal collection. The ingot obtained after the fixed-point metal was completely melted is shown in Fig. 3(a).

When the necessary amount of aluminium was obtained, a graphite thermometer well was then placed upon the aluminium ingot at its closed end, while upon its open end, some graphite balancing weights were stacked so that their total weight would be slightly greater than the buoyant force of the liquid aluminium that may arise on the graphite thermometer well during melting. The crucible, the thermometer well and the balancing weights were then enclosed in a quartz cylinder sealed by its cap. A quartz rod was used to seal the cylinder assembly. This cylinder assembly is shown in Fig. 3(b).

The cylinder assembly was set in a furnace and degassed using a vacuum pump until a considerably high vacuum (the order of $10^{-5} \mathrm{~Pa}$ ) was achieved, then pressurized by argon gas introduced through the gas port. Under pressurized argon gas, the asembly was heated inside the furnace where the temperature was set some kelvins higher than the melting point of aluminium until the ingot completely melted. The gravitational force from the balancing weights caused the graphite thermometer well to move down into the graphite crucible. Since the upper part of the graphite thermometer well was cooler than the lower part that was in direct contact with the melted ingot, the upper part of the ingot froze whenever the graphite thermometer well moved down. After the frozen part remelt-

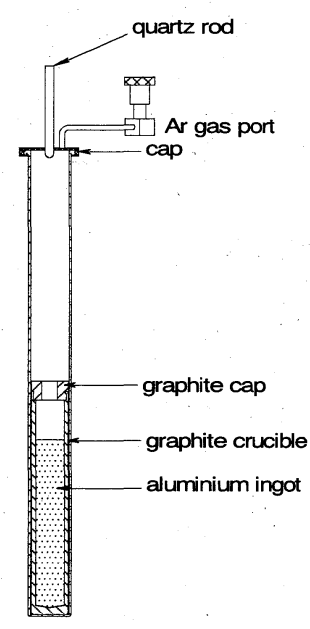

(a)

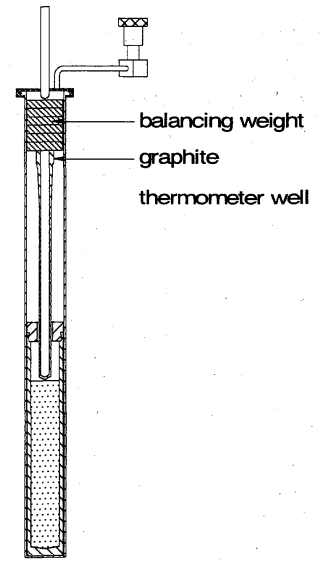

(b)

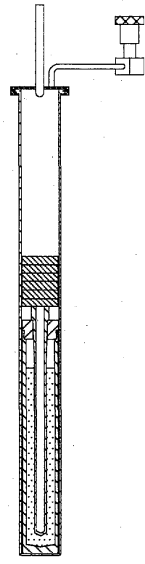

(c)
Fig. 3 Metal filling method 1: (a) set-up after melting the aluminium pellets, ( b ) set-up before and (c) after the insertion of the graphite thermometer well ed, further sinking of the graphite thermometer well continued. This process occurred several times until the graphite thermometer well came to its lowest possible position within the graphite crucible. The tapered part at the "neck" of the graphite thermometer well caused it sink vertically into the ingot at the center of the crucible. The furnace temperature was then set some kelvins below the freezing temperature of aluminium to solidify the ingot. After the ingot was completely solidified, the temperature of the furnace was brought down to room temperature.

\section{3 Metal-Filling Methods: Method 2}

In the second method using the aluminium rod, Method 2 , since no prior metal filling, as performed in the case using aluminium pellets, was needed, the setup shown in Fig. 4 (a ) became the first procedure in this method.

The next procedure was similar to that in Method 1: the cylinder assembly shown in Fig. 4(a) was set in the furnace, degassed to high vacuum, and pressurized by argon gas in which it was heated inside the furnace with the temperature set some kelvins higher than the melting point of aluminium until the rod completely melted. The gravitational force from the balancing weights pushing the graphite thermometer well helped it to move down into the graphite crucible. When the thermometer well arrived at its lowest possible position within the crucible, the furnace temperature was set some kelvins below the freezing temperature of aluminium to start the solidification of the melted aluminium. After the ingot was completely. solidified, the temperature of the furnace was brought

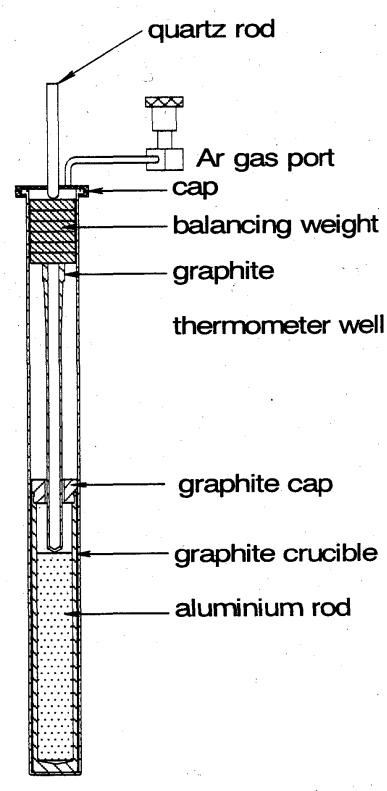

(a)

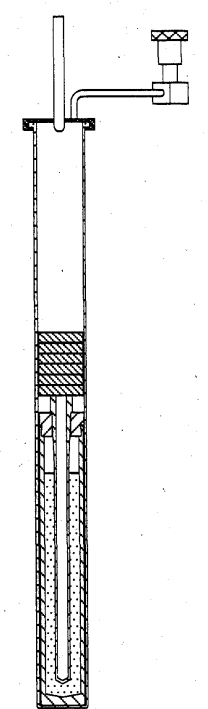

(b)
Fig. 4 Metal filling method 2: (a) set-up before, and (b) after the insertion of the graphite thermometer well 
down to room temperature.

In both methods, after the aluminium filling, the cylinder assembly was opened within the gas chamber to install the graphite wool as heat insulator, afterwhich the fixed-point cell was completed. The fixed-point cell was then degassed before being pressurized by high-grade (G1, purity: 99.9999\%) argon gas. For identification, the fixed-point cell developed using Method 1 is coded Al No. 4, while that using Method 2 is coded Al No. 5. That fabricated using the conventional method, Method O, is coded Al No. 1 and is used for comparison.

The basic concept of both Method 1 and Method 2 is the same as that reported by Nubbemeyer ${ }^{5)}$, where the graphite thermometer well was inserted into the melted metal with the aid of a pressing rod pushed down from the outside of the cell assembly. Recent work concerning the fabrication of the fixed-point cell based on a similar method was reported by Edler and Baratto ${ }^{6)}$ who constructed a relatively small fixed-point cell.

We have also fabricated an aluminium fixed-point cell by Nubbemeyer's method, as already reported elsewhere ${ }^{7)}$, from which we identified some weak points of the method. The first was that pushing the pressing rod from the outside of the cell assembly during the insertion of the graphite thermometer well requires opening the assembly ; this may lead to the introduction of contaminants into the cell assembly. Particularly for the case where a large amount of metal and a long graphite thermometer well are used to enable a greater metal immersion depth, a temperature gradient develops between the melted metal and the thermometer well, causing the metal surrounding the inserted thermometer well to freeze. Then, the insertion process should be stopped until the frozen metal melts again. As a consequence, the duration of opening the cell assembly during the insertion process becomes longer so that the probability of contamination becomes higher. The second weak point was that if the pressing rod is pushed excessively during the insertion of the thermometer'well while the surrounding metal froze, crack may be formed over the crucible, thermometer well or other parts. It is difficult to adjust the pressing force appropriately.

As an alternative to Nubbemeyer's method, we proposed, in the present work, the use of adjustable balancing weights that enables the graphite thermometer well to be inserted safely in a closed space so that contamination can be prevented.

\section{Evaluation of the Developed Aluminium Cells}

\subsection{Temperature Measurements during Freezing}

The improvement of the proposed metal-filling methods was evaluated in the present study first by making comparisons among the freezing curves of the aluminium point cells owned by NMIJ, including the newly constructed ones. The freezing curve was obtained through temperature measurements during the solidification process of liquid aluminium. One fixed-point furnace and one standard platinum resistance thermometer (SPRT) were used throughout the temperature measurements. The cell was connected to a buffer gas tank filled with high-grade argon gas, which is used to keep the pressure stable during the measurements. The furnace temperature was set $0.6^{\circ} \mathrm{C}$ below the aluminium freezing point, as per our standard procedure in the calibration services for SPRTs at the aluminium point. The temperature control of the furnace to realize the freezing point of aluminium has already been reported elsewhere ${ }^{2)}$.

From the temperature change and the frozen (or melted) fraction of aluminium, it is possible to construct a freezing curve in terms of the temperature difference from the freezing point at any point designated by $1 / F$, where $F$ defines the liquid fraction of the aluminium, as given in eq. (1).

$$
F=\frac{L}{S+L}
$$

$L$ and $S$ in eq. ( 1 ) stand for the liquid and solid fractions, respectively, with the overall amount of the aluminium being $S+L$. Since the rate of solidification was set to be constant, which was achieved by fixing the difference of the furnace temperature from the freezing point, the melted or frozen fraction would be proportional to the time fraction from the initial time to the final point of melting or freezing. The temperature difference from the freezing point is converted from the difference in the resistance of the SPRT used during metal freezing from the value at $1 / F=0$ extrapolated for each curve.

Fig. 5 represents the freezing curves of the conventional aluminium point cell, designated Al No. 1, which was developed using aluminium pellets ( $6 \mathrm{~N}$ purity), and that of Al No. 4 developed in the present study using the same type of aluminium with the same nominal purity. The temperatures measured between $F=0.67$ and 0.286 were used to extrapolate the value at $1 / F=0$, a hypothetic ideal pure condition ${ }^{2}$. The temperature difference at any $1 / F$ from the value at $1 / F=0$ is taken in this figure as its ordinate, $T_{1 / F}-T_{1 / F}=0$. It should be noted, however, that 


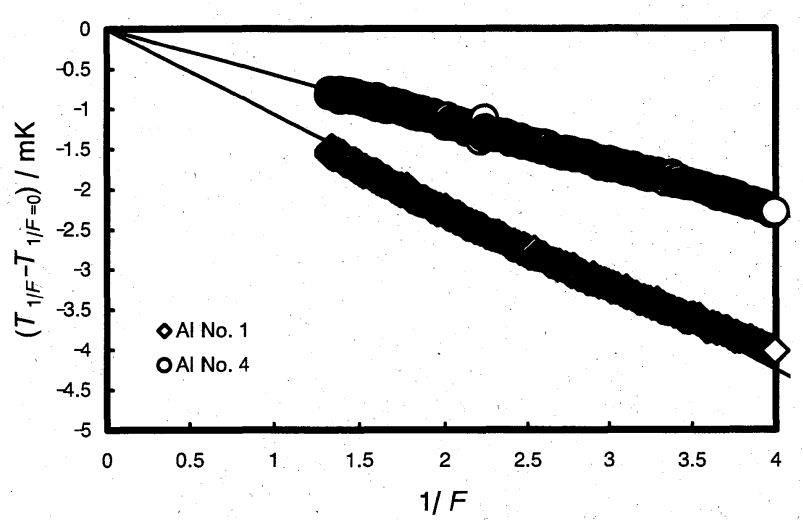

Fig. 5 The freezing curves of aluminium-point cells fabricated using aluminium pellets, $\mathrm{Al}$ No. 1 and $\mathrm{Al}$ No. 4

the resistance of the SPRT at $1 / F=0$ in one cell may be different from that in the other cells due to any slight shift after one series of measurements. The solid lines represent the gradient of the freezing curves. The freezingpoint depression is shown by the temperature difference at $1 / F=1$. In general, the less contaminated (or more pure) the fixed-point metal, the smaller the depression (or the gradient) of its freezing point will be.

Fig. 5 shows that the freezing-point depression of the newly developed aluminium point cell, $\mathrm{Al}$ No.4, is significantly smaller than that of the conventional one. The gradient of the freezing curve is around half that of the conventional cell. This may imply that the proposed filling method, Method 1, gives significant improvement in the realization of an accurate aluminium point, namely, in preventing any contamination during metal filling.

One may agree that it is somewhat premature to conclude, from the present results, that the above improvement is the effect of reducing the number of melt-freeze processes during the aluminium filling, since the cells are from different aluminium lots and there is no detailed information on the impurity elements within the lots used. Although the nominal purities are similar, different elements may contribute differently to the realization of the freezing temperature of aluminium.

In a report, based on the rsults of an international cell comparison where cell Al No. 1 was also taking part, Fellmuth et al. $^{8}$ derived a typical uncertainty due to impuritics in aluminium point realization done by the currently available method using $6 \mathrm{~N}$ grade aluminium. The typical uncertainty is $1.5 \mathrm{mK}$, which is on the same level as the freezing-point depression showed by cell $\mathrm{Al}$ No. 1. From the above reported result, it could be assumed that the dominant impurities among $6 \mathrm{~N}$ grade aluminium lots available at one time are similar. Accordingly, consid-

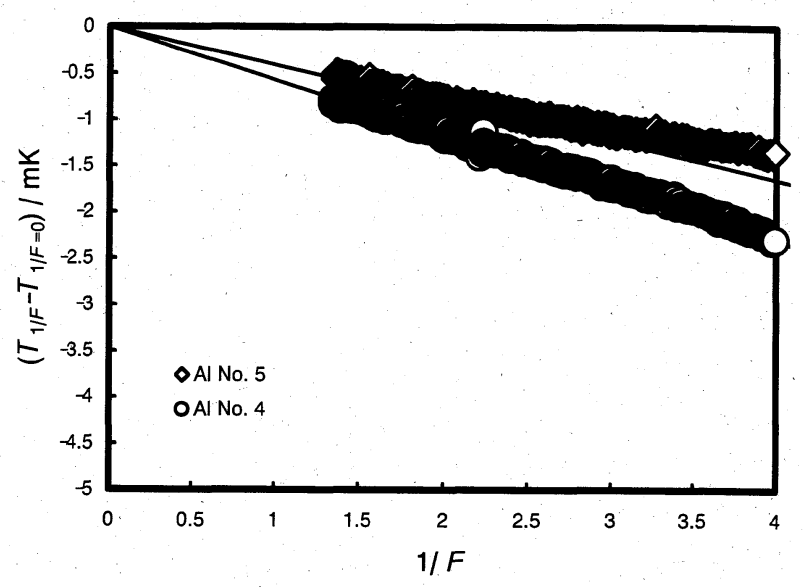

Fig. 6 The freezing curves of the aluminium-point cells fabricated using pellet-type aluminium, Al No. 4, and using single-rod type aluminium, Al No. 5

cring that the $6 \mathrm{~N}$ grade aluminium used was also the typically available one and that the fixed-point realization method used was conventional, the difference between cell $\mathrm{Al} \mathrm{No} 4$ and the conventional cell represented by cell $\mathrm{Al}$ No. 1 would come from the method of metal filing. This makes us confident that our proposed metal-filling method has brought a significant improvement.

Fig. 6 illustrates the freezing curves of $\mathrm{Al} \mathrm{No.} 4$ and $\mathrm{Al}$ No. 5. The scale of the figure has been adjusted to enable a clear comparison with the curves for Al No. 1 and Al No. 4 cells shown in Fig. 5.

As shown in Fig. 6, the freezing curve of A1 No. 5 has smaller gradient than that of Al No. 4. This fact may indicate the effectiveness of using a single rod compared with the use of pellets. As described previously, the adoption of single-rod aluminium led to only one meltfreeze process during metal filling. From the comparison of the freezing curves in Fig. 5 and 6, it can be concluded that cell Al No. 5 is less contaminated than cells Al No. 4 and $\mathrm{Al} \mathrm{No} 1$ because its freezing curve has the smallest gradient.

\section{2 Direct Cell Comparison Measurements}

The above temperature measurements have been used to compare indirectly the developed cells with the conventional one. They also allowed us to confirm whether or not the cells constructed work well. However, such results must be reconfirmed by direct comparison, since the above measurements were not simultaneous so that the SPRT used shifted slightly after one series of measurements. Only the temperature difference from one specified point (in the above case: the freezing point realized by each cell), but not the absolute temperature, can be compared from such measurements. 
計測自動制御学会論文集

Table 1 Temperature difference between cells

\begin{tabular}{c|c|c}
\hline \hline Cells $(\text { method })^{*}$ & $\Delta T_{\text {against A1 No. 5 }} / \mathrm{mK}$ & Uncertainty**/mK \\
\hline Al No.5 (method 2) & 0 & - \\
\hline Al No. 1 (method 0$)$ & -0.9 & 0.1 \\
\hline Al No.4 (method 1) & -0.2 & 0.2 \\
\hline
\end{tabular}

*.word in the bracket shows the metod of metal filling used

** derived from the standard deviation of four data

In cell comparisons in the present study, we introduced a commercial sealed aluminium cell (Isotech), coded A1 No. 102 in this study, which had been calibrated (directly. compared) against the Al No. 1 cell, as reported elsewhere ${ }^{9)}$. Three sodium heat-pipe fixed-point furnaces were prepared, the first one for the sealed cell, the second one for the Al No. 5 cell and the third one for the Al No. 4 cell. Direct comparisons were conducted consecutively between Al No. 5 and Al No. 102 cells and between Al No. 5 and Al No. 4 cells using one SPRT. From such measure; ments, the cell differences among Al No. 1, Al No. 4 and $\mathrm{Al}$ No. 5 cells can at least be obtained, since the Al No. 102 cell was already calibrated against the Al No. 1 cell.

Direct cell comparison between cells $\mathrm{Al}$ No. 5 and $\mathrm{Al}$ No. 102 was conducted in four series of measurements during four different freezing processes. The temperature difference between cells was measured at $1 / F=1.33$, termed for the purpose here as the aluminium point ${ }^{9}$. Using the results of the calibration of the Al No. 102 cell against the Al No. 1 cell, it was found, as listed in Table 1, that the aluminium point realized in the Al No. 5 cell is higher than that in the Al No. 1 cell. The temperature difference between cells shown in Table 1 is given as the difference from the aluminium point realized in the Al No. 5 cell, $\Delta T_{\text {against A1 No. } 5 \text {. }}$

Direct cell comparison between cells $\mathrm{Al}$ No. 5 and $\mathrm{Al}$ No. 4 was performed in four series of measurements along four different freezing processes. The results are also tabulated in Table 1 , and show that the aluminium point realized in the Al No. 5 cell is higher than that in the $\mathrm{Al}$ No. 4 cell.

Based on our cell comparison results, the order of the realized fixed-point value would be: the Al No. 5 cell as the highest followed by the $\mathrm{Al}$ No. 4 cell and then the $\mathrm{Al}$ No. 1 cell. This order is in accordance with the results obtained by comparing the freezing curves of the fixedpoint cells, as shown in Fig. 5 and 6. The most important finding in the above measurements is that the fixed point depression has been reduced significantly by the proposed metal filling methods as given by Table 1 . This will lead to the reduction of the measurement uncertainty due to the impurity effect.

The present study is by no means our final work in developing reliable fixed-point cells which will be used to establish and disseminate temperature standards in Japan. This study is being continued by the development of several fixed-point cells along with their respective measurements to confirm the reliability of the method proposed here, even for other fixed points. It is particularly interesting to compare the multi step metal-filling method and the single-step one, as discussed in the present paper, using metal samples from the same source (one lot). Such comparisons may show more precisely the significance of the filling method proposed here.

\section{Conclusion}

Two aluminium point cells were constructed on the basis of new metal-filling methods. High-purity aluminium ( $6 \mathrm{~N}$ nominal) in the form of a single rod and pellets were used to fabricate the new cells. The new metalfilling method was customized according to the form of the aluminium used. Temperature measurements during freezing were conducted to determine the fixed points realized in the newly constructed cells as well as in the existing cell, the comparisons of which imply that the newly proposed metal-filling method, as well as the cell design, is a significant improvement in the realization of the aluminium point. Direct cell comparison was also performed to measure the temperature difference among the fixed points realized in the newly constructed and the existing cells. As a result, the indirect comparison, based on the freezing curves of the cells, was found to be in accordance with the direct cell comparison. This result reconfirms the reliability of our proposed metal-filling method and cell design. From those measurements, it was also found that the proposed methods significantly reduce the uncertainty of fixed-point realization.

\section{Acknowledgements}

The author is indebted to Mr. Kenichi Suzuki and Mr. Kazutoshi Kakita from Nippon Steel Techno Research Co., Ltd. for providing the aluminium rod used in the new aluminium cell in the present work. The aluminium rod was the product of a research project under their coordination.

\section{References}

1) H. Preston-Thomas: The International Temperature Scale of 1990 (ITS-90), Metrologia, 27, 3/10 (1990)

2) M. Arai and K. Harada: Uncertainty Assessment on the Freezing Point of Aluminium in the ITS-90, Netsu Bussei, 
$12-4,205 / 210$ (1998)

3) M. Arai and K. Harada: Uncertainty Assessment on the Freezing Point of Silver in the ITS-90, Netsu Bussei, 14-4, 278/283 (2000)

4) K. Suzuki and S. Kakita: Dainiki Seika Houkokusho, Kagaku-gijutsu Shinko Chouseihi, 302/310 (2002)

5) H. G. Nubbemeyer: High Temperature Platinum Resistance Thermometers and Fixed-point Cell for the Realization of the ITS -90 in the Range $0^{\circ} \mathrm{C}$ to $961.78^{\circ} \mathrm{C}$, Temperature 6, 199/202 (1992)

6) F. Edler and A.C. Baratto: A Cobalt-Carbon Eutectic Fixed Point for the Calibration of Contact Thermometers at Temperatures above $1100^{\circ} \mathrm{C}$, Metrologia 42, 201/207 (2005)

7) J. V. Widiatmo, K. Harada, I. Kishimoto and M. Arai: Development of a New Aluminium-Point Cell, Proceedings of SICE 2003 1227/1230 (2003)

8) B. Fellmuth, J. Fischer and E. Tegeler: Uncertainty Budgets for Characteristics of SPRTs Calibrated according to the ITS-90, CCT Document CCT/01-02

9) M. Arai and K. Harada: A Method for Realizing the High-Temperature Fixed-Points of the ITS-90 by Using a Single Liquid-Solid Interface, Netsu Bussei, 13-4, 258/264 (1999)

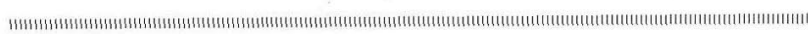

\section{Januarius V. Widtatmo}

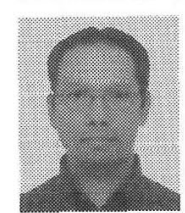

He graduated from the Graduate School of Science and Technology, Keio University with $\mathrm{PhD}$ degree in engineering in 1996. He was a research associate at the Faculty of Science and Technology, Keio University, before joining the National Metrology Institute of Japan within the National Institute of Advanced Industrial Science and Technology (NMIJ, AIST) in 2002. His current research interests are temperature standards and thermophysical properties.

\section{Katsuhiko HARADA}

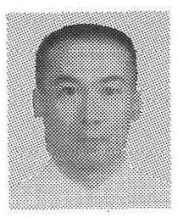

$\mathrm{He}$ jointed the National Institute of Advanced Industrial Science and Technology (AIST) in 1983, being engaged in the inspection of standard device, the evaluation for pattern approval, and the dissemination and research of temperature standards. Since 2001 he is affiliated to the legal metrology division of the National Metrology Institute of Japan (NMIJ), AIST, co-working with the thermometry section of the temperature and humidity division of the NMIJ.

\section{Masaru AraI (Member)}

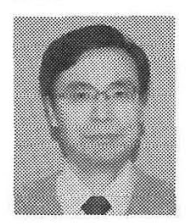

He graduated from the Tokyo Institute of Technology with M.S. degree in science in 1984. In the same year, he jointed the National Institute of Advanced Industrial Science and Technology (AIST) with principal interest in temperature standards. He was a research associate at the Intituto di Metrologia " $G$ Colonnetti" (IMGC), Italy in 1994. In 2001, he was affiliated to the National Metrology Institute of Japan (NMIJ), AIST. His present affiliation is the Planning Headquarters, AIST. 